\title{
Surface treated natural rubber latex sludge as a potential filler for natural rubber compounds
}

\author{
U M S Priyanka*, U N Rathnayake** and S Siriwardena* \\ * Rubber Research Institute of Sri Lanka, Telawala Road, Rathmalana, Sri Lanka \\ ** Hayley's Group - Dipped Products PLC, 400, Deans Road, Colombo 10, Sri Lanka
}

\begin{abstract}
Natural rubber (NR) latex sludge, a byproduct generated from centrifuged latex manufacturing industry, contains a large portion of inorganic materials and presently treated as a waste material. In this study, the sludge was converted to a powdery material through drying and grinding processes followed by a surface modification with a long chain fatty acid with a view improving its compatibility with rubber composites.

Composition and structure analysis of the latex sludge powder showed that it is mainly a crystalline material of phosphate mineral with approximately $8 \%$ of trapped rubber particles within the sludge material. Processed NR latex sludge powder was surface treated with a long chain fatty acid to offer organophilic character to the sludge. FTIR analysis confirmed that latex sludge was successfully modified with the long chain fatty acid.

A series of NR compounds were prepared with different loading levels of the surface treated sludge using a laboratory scale internal mixer to study the effect of the surface modified sludge on curing and mechanical properties in comparison to unmodified latex sludge filled NR compounds. Curing characteristics measured under low shear strain rate have shown that surface modification improves the processing safety without a significant impact on other curing characteristics.

Mechanical properties of surface treated sludge filled NR vulcnizates have shown an improvement in tensile properties, especially strength and elongation at break, in comparison to untreated counterparts. However, on the other hand, stiffness as measured with hardness was reduced at higher loadings of surface treated sludge filled $N R$ vulcanizates. Both surface treatment and the increase of filler loading increased the compression strength and abrasion weight loss of the compounds.
\end{abstract}

Key words: fatty acids, mechanical properties, Natural rubber, NR latex sludge, surface treated

\section{Introduction}

Fillers are a group of materials frequently incorporated in to rubber composites as one of the major additives among all the other rubber compounding ingredients such as activators, accelerators, vulcanizing agents, antioxidants, softeners, thickeners, etc. 
U M S Priyanka et al.

to meet various product performance requirements (Okiemen et al., 2003). It has been well established for decades that incorporation of filler has two main advantages; improvement of the reinforcement of the rubber composites and/or reduction of the cost of the final product (Hepburn \& Blow, 1971). Incorporation of reinforcing filler into NR matrix improves physicomechanical properties such as oil resistance, abrasion resistance and tensile strength of rubber vulcanizate by increasing the number of cross-links in rubber chains, which share load applied to the matrix. The reinforcement efficiency of the particulate filler depends on particle size, particle size distribution, particle shape, surface activity, and the interaction between the filler and the rubber matrix. (Ski, 1970; Parkinson, 1957; Hepbium, 1984). Non reinforcing fillers, known as diluents increase the bulk volume of the composite while reducing the cost of the materials.

A large number of studies on effective usage of various industrial and agricultural by-products such as wood flour, rice husk, palm kernel husks, fly ash as low cost filler materials, in rubber composites has been reported by many research groups (Okiemen \& Imanah, 2003; Sae- Oui, P. et al., 2002; Muniandy et al., 2012; Pangamol et al., 2018). These studies have revealed that the use of such materials in NR composites has multiple benefits such as low cost, certain property enhancements and in addition, the positive environmental impacts offered by restricting their disposal to the environment. However, preparation of rubber composites filled with these types of fillers derived from industrial waste materials to yield useful technical properties, overcoming unnecessary agglomeration within the rubber matrix, is a challenging task.

Surface modifications of filler using various modifiers such as titanates, silanes, phosphates, fatty acids etc. have been widely reported as one of the main techniques to overcome the above challenge (NikNurAzzaNikAdik et al., 2016). Stearic acid, a low molecular weight organic compound, has been used successfully to modify the surface of the different filler types like calcium carbonate and magnesium hydroxide. Coating with stearic acid on filler surface can improve the compatibility between rubber matrix and the coated filler, resulting in improved interfacial interaction and improved uniform dispersion within the rubber matrix due to the bi functional character (polar head and non-polar tail) of the stearic acid structure. Consequently, rubber composites with improved properties could be generated (Mihajlovc et al., 2009).

Latex sludge containing magnesium ammonium phosphate which is a byproduct generated in the magnesium removal process during centrifuged latex manufacturing process is one of the potential source for deriving a such low cost filler. Manufacture of $100 \mathrm{~kg}$ (dry rubber) of concentrated NR latex generates about $4-5 \mathrm{~kg}$ of latex sludge. This is a considerable quantity when consider the total concentrated latex production of approximately 30,600 MT 
(Rubber Development Department, 2016). In general practice, this sludge is disposed as a waste material, creating environmental issues such as emanating bad smell, contamination of water bodies and increasing the soil basicity. Even though agronomic benefits of the latex sludge have been investigated (Okiemen et al., 2002), there is no reported literature available on its wide usage in the agriculture sector. This may be probably due to the presence of rubber particles trapped in the sludge which could decrease the rate of biological degradation. Effect of natural rubber processing sludge on the degradation of crude oil hydrocarbons in soil has also been investigated and found out that the extent of crude oil degradation was markedly increased by the sludge (Okieimen \& Okieimen, 2002). A study on potential use of sludge ash as a filler in NR has revealed that there is a potential of using sludge ash as filler in the rubber industry (Intiya et al., 2016). Use of untreated sludge as a semi reinforcing filler along with Carbon black for NR compounds has been reported by (Priyanka \& Rathnayake, 2012). This study has revealed the use of sludge as a partial filler in carbon black filled rubber composites suitable for selected industrial applications.

Modification of sludge surface is a potential route to achieve the improved compatibility between latex sludge filler and the rubber matrix and subsequent enhance the dispersibility, widening its applications in the rubber industry.

Therefore, this study was carried out to investigate the effect of surface modification of latex sludge on the performance of NR compounds filled/treated sludge. Sludge material was first characterized for its chemical composition and structure. Filler surface was treated with stearic acid and curing and mechanical performances of latex sludge filled NR compounds were investigated with a view to studying the effect of surface modification of latex sludge.

\section{Materials and Methods Materials}

RSS No 1 grade of natural rubber obtained from Dartonfield Factory, Rubber Research Institute of Sri Lanka was used as the rubber material. NR latex sludge, a by-product of centrifuged latex manufacturing process, used in this study was obtained from Lalan Rubber (Pvt.) Ltd., Bulathsinghala, Sri Lanka. Other compounding ingredients used were of commercial grade chemicals supplied by local rubber chemical suppliers.

The latex sludge collected from Lalan Rubber (Pvt.) Ltd., was first sun dried for 4 days and further dried at $100^{\circ} \mathrm{C}$ in an oven for 24hrs and ground in to a powder. This powder was further dried at $120^{\circ} \mathrm{Cin}$ an oven for $2 \mathrm{hrs}$ to assure a moisture free material.

Preparation of surface treated sludge A volume of water $(172 \mathrm{ml})$ was heated to $75{ }^{\circ} \mathrm{C}$ and stearic acid (20.3 g) was added in to the heated water. The mixture was further heated for another $15 \mathrm{~min}$. Ammonia solution ( $25 \mathrm{w} / \mathrm{w} \%$ ) was then added while stirring and the mixture was homogenized for 30min. Sludge suspension was prepared by mixing 640 g dried sludge powder into $3.2 \mathrm{~L}$ of 
U M S Priyanka et al.

water. The temperature of the suspension was adjusted to $75^{\circ} \mathrm{C}$. Two mixtures were then mixed together and the mixture was stirred for one hour at $75^{\circ}$ C. Coated sludge was separated off and dried in an oven at $55^{\circ} \mathrm{C}$ for, 24hrs, and again ground to a fine powder.

\section{Characterization of latex sludge}

Chemical composition, especially metal iron concentration, of dried latex sludge powder was characterized with Atomic Absorption Spectrophotometer (AAS), model GBC Avanta l, whilst phosphate content was determined using ASTM 4500-P (Vandomolybdophosphoric acid colorimetric method).

Structural analysis of sludge carried out using an X-ray diffractometer (Bruker D8 diffractometer and the analysis was performed at a wave length of $1.54 \AA$ of $\mathrm{Cu} \mathrm{K} \alpha$ radiations to determine the crystalline structure of the sludge,

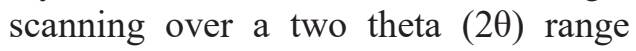
from 1 to 60 degrees, at a rate of $0.01 \%$ seconds.

Rubber hydrocarbon content, acetone extract, and volatile material content were determined using ISO test methods, ISO 5945-19 2E, ISO 1404 and ISO 1976-E, respectively.

Fourier Transmission Infra-red Spectroscopy (FTIR) analysis was carried out in order to find out the presence of stearic acid coating on the latex sludge using Nicolet 380 FTIR spectrometer. The analysis was done within the wavelength range of 400 to $4000 \mathrm{~cm}^{-1}$.

The morphology of the sludge particles were studied with the HITACHI SU 6600 scanning electron microscope after the samples were sputter coated with a thin gold layer.

\section{Compounding}

Table 1 shows the formulation for each compound containing different loading levels of coated and uncoated sludge as filler.

For the compounding and mixing, a Brabender plasticorder (model: PL2000) was used. Latex sludge filled NR composites were prepared by mixing them in the Brabender for 15 minutes at temperature of $60{ }^{\circ} \mathrm{C}$ and rotor speed of 60rpm. Various rubber additives were added to the masticated natural rubber prior to the addition of NR latex sludge and carbon black. Finally, accelerator and sulfur was added. Six natural rubber composites were produced incorporating different sludge loading levels from 0 100 phr at 20 phr intervals. 
Sludge from NR latex as a filler in rubber compounds

Table 1. Formulations of sludge filled NR composites

\begin{tabular}{lcc}
\hline Ingredients & \multicolumn{2}{c}{ Amount (phr) } \\
\cline { 2 - 3 } & $\begin{array}{c}\text { Uncoated } \\
\text { Sludge filled } \\
\text { Composites } \\
\text { (USC) }\end{array}$ & $\begin{array}{c}\text { Coated } \\
\text { Sludge filled } \\
\text { Composites } \\
\text { (CSC) }\end{array}$ \\
\hline Natural Rubber (RSS) & 100 \\
Zinc oxide & \multicolumn{2}{c}{5.0} \\
Stearic acid & 2.0 \\
N-isopropyl n-phenyl1,4-phenylendiamine & 1.0 \\
Carbon black & 30 \\
N-cyclohexyl-2-Benzothiazole sulphenamide (CBS) & \multicolumn{2}{c}{1.2} \\
Tetramethyl thiuram monosulfide (TMTM) & \multicolumn{2}{c}{0.4} \\
Sulfur & \multicolumn{2}{c}{2.0} \\
Processing oil & \multicolumn{2}{c}{5.0} \\
Sludge uncoated & Variable & $(0-100)$ \\
Sludge coated with stearic acid & - & Variable $(0-100)$ \\
\hline
\end{tabular}

\section{Cure characteristics}

Cure characteristics of the composites were determined using a moving die rheometer, model (MDR:Ekron EKT2000s) according to ASTM 5289 at 130 ${ }^{0} \mathrm{C}$. Cure characteristics of the latex sludge filled NR compounds were derived from the respective rheographs.

\section{Mechanical properties}

NR vulcanisates were prepared by compression molding of rubber compounds according to respective optimum cure times $\left(\mathrm{t}_{90}\right)$ using a Hot press (KAO-Tech compression Moulding Machine) at $130^{\circ} \mathrm{C}$. Tensile properties and tear strengths of the rubber vulcanisates containing coated and uncoated sludge were analyzed using an Instron, model 3365 Universal
Tensometer following ASTM D 412-68 and ASTM 624-54 standards methods respectively. Five specimens were analyzed from each composite and the average results were recorded.

\section{Results and Discussion \\ Composition and structure characterization}

Composition of the latex sludge dried at $120^{\circ} \mathrm{C}$ is presented in Table 2 . The results show that magnesium and phosphorus are the main inorganic constituents in the sludge. There is also a considerable amount of polyisoprene which indicates the natural rubber (measured as polyisoprene) trapped in the sludge material. Volatile matter percentage is about $5.54(\mathrm{w} / \mathrm{w})$ which consists of both ammonia and moisture of the sample. 
U M S Priyanka et al.

Table 2. Chemical composition of NR latex sludge dried at $120^{\circ} \mathrm{C}$

\begin{tabular}{ll}
\hline Constituent & (w/w \%) \\
\hline Oxygen (based on phosphate content) & 36.0 \\
Magnesium & 27.73 \\
Phosphorus & 18.26 \\
Poly isoprene content & 8.31 \\
Volatile matters & 5.54 \\
Ammonical Nitrogen content & 0.16 \\
Zinc & 0.001 \\
Other materials & add to 100 \\
\hline
\end{tabular}

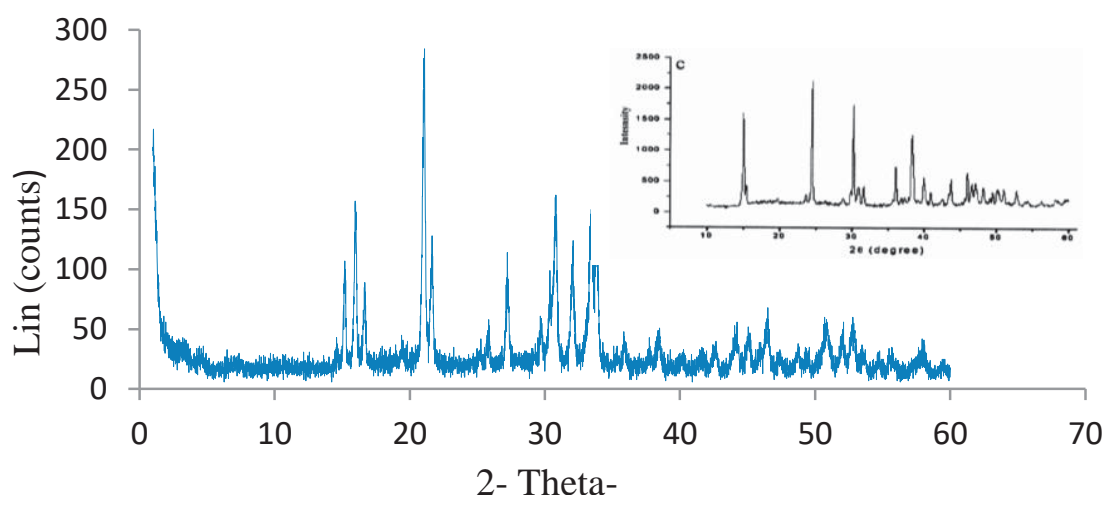

Fig. 1. The XRD spectrum of uncoated NR latex sludge

The diffraction peaks are appeared at 15 ${ }^{0}, 45^{0}, 46^{0}$, and $47^{0}$ in the -XRD spectrum of the sludge are analogous with the characteristic peaks for magnesium ammonium phosphate hexahydrate $\left(\mathrm{MgNH}_{4} \mathrm{PO}_{4} .6 \mathrm{H} 2 \mathrm{O}\right)$, a phosphate mineral known as struvite. Therefore, $\mathrm{XRD}$ analysis suggests that sludge is a phosphate rich mineral with a structure similar to struvite (Fig.1).

\section{Morphological studies}

Figure 2 (a) illustrates the SEM micrographs of the latex sludge. It could be seen that uncoated sludge particles exist as agglomerates with irregular sizes and shapes. SEM micrographs of the sludge observed at higher magnification are shown in Figure 2 (b). It clearly shows platelet like laminated sheets structure of the sludge particles. Due to these laminated structure, sludge particles have a higher aspect ratio, which has a potential reinforcing effect in a polymeric composites matrix. When the micrographs of untreated and surface treated filler samples at same magnification (Figures 2(a) and 2 (c) are compared, agglomerates of relatively smaller sizes could be seen in surface treated sludge. It could be suggest that the surface coating has restricted the sludge particle agglomeration to a certain extent. 


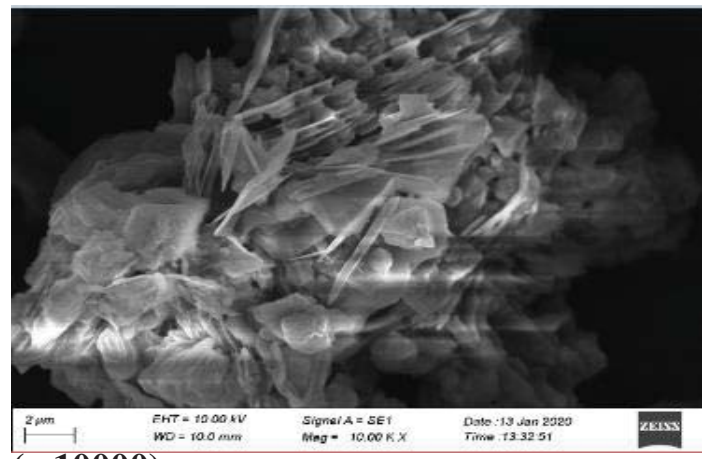

(x 10000)

a. Uncoated sludge particles

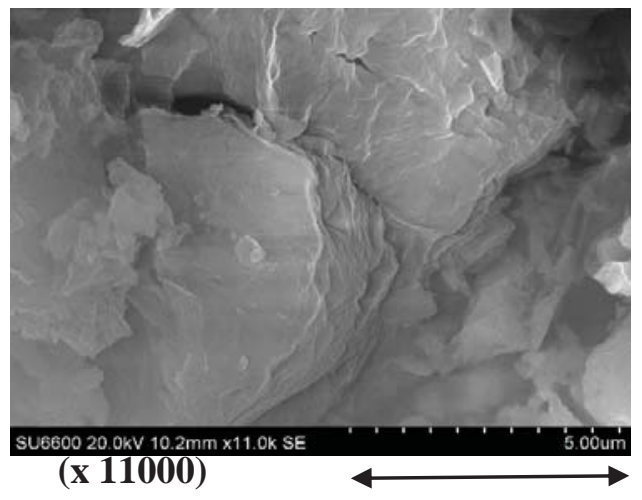

b. Uncoated sludge particles higher magnification

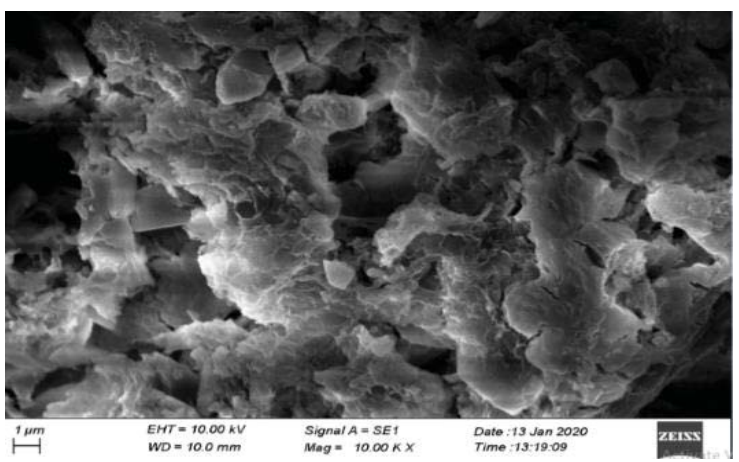

\section{(x 10000)}

c. Coated sludge particles

Fig. 2. Illustrates the SEM micrographs of the sludge

\section{FTIR analysis}

Figure 3 shows the infrared spectra of coated sludge and uncoated sludge samples. Peaks at $2326 \mathrm{~cm}^{-1}$ due to stretching vibration of NH4 group, 1480 $\mathrm{cm}^{-1}$ due to bending and vibration of crystalline water, 1070, 990 and 913 $\mathrm{cm}^{-1}$ peaks due to bending and vibration of $\mathrm{PO}^{-3}$ (Stefov et al., 2005) they are common to both coated and uncoated spectrums and further confirmed the sludge as crystalline magnesium ammonium phosphate hexahydate. IR band appear at $1241 \mathrm{~cm}^{-1}$ due to $\mathrm{CO}-\mathrm{O}$ stretching in esters and two additional peaks at $2854 \mathrm{~cm}^{-1}$ and $2919 \mathrm{~cm}^{-1}$ seen in the FTIR spectrum of coated sludge. These two additional peaks correspond to symmetric and asymmetric stretching and vibrations of aliphatic groups $-\mathrm{CH}_{2}-$ groups. Presence of these peaks in the spectrum of stearic acid coated sludge suggests that, there is $\mathrm{CO}-\mathrm{O}$ groups and $\mathrm{C}-\mathrm{H}$ bonding typical to $\mathrm{CH}_{2}$ groups of stearic acid $\left(\mathrm{CH}_{3} \quad\left(\mathrm{CH}_{2}\right)_{16} \mathrm{COOH}\right)$. Therefore, it is evidenced that modification of the sludge surface with stearic acid is successful. 

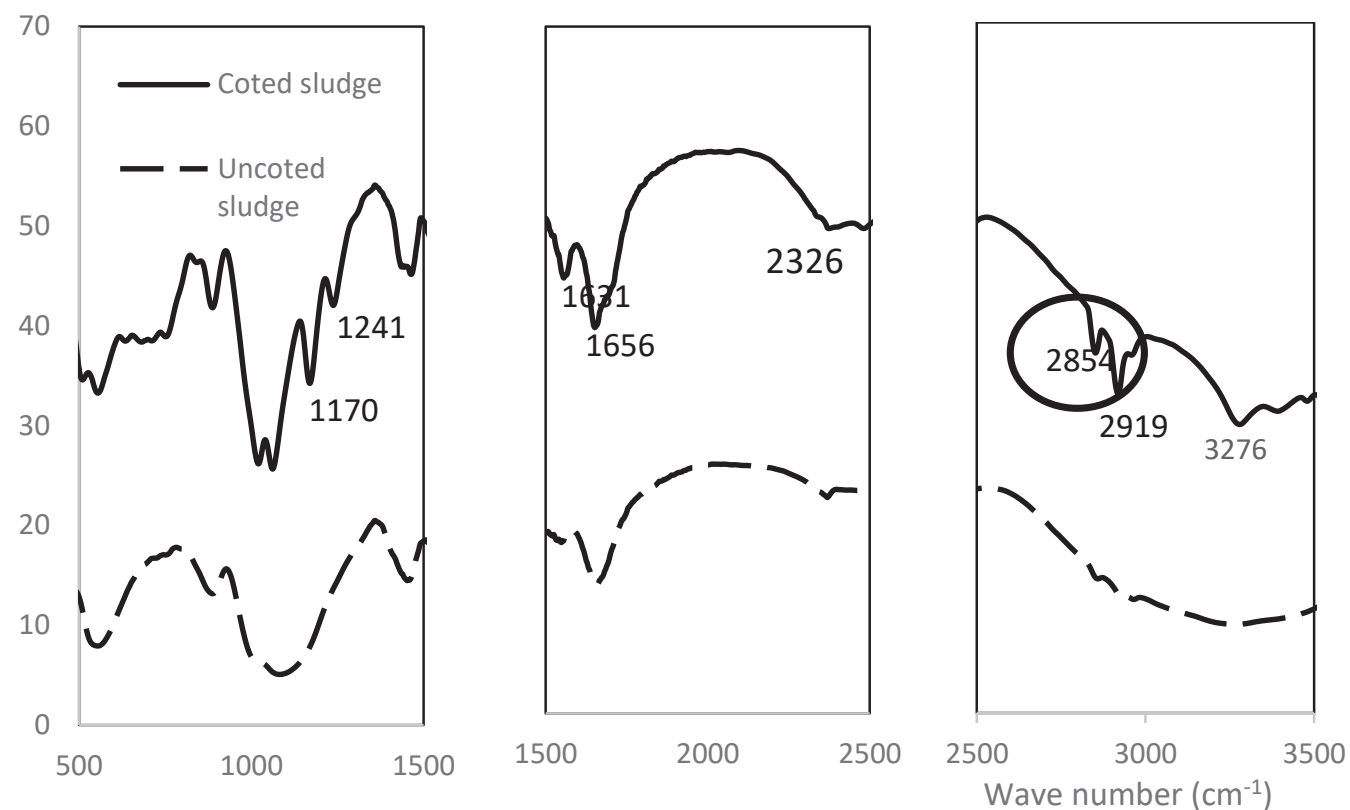

Fig. 3. FTIR of Stearic acid coated and uncoated sludge

Cure characteristic and processability of NR/sludge compounds

Figures 4 to 8 show the effect of stearic acid coated sludge and uncoated sludge on the curing characteristics of the rubber compounds.

Figure 4 shows that incorporation of sludge has initially resulted an increase in the scorch time in both uncoated and coated composites. Maximum increase was registered at 20phr sludge loading for both types of compounds. For unmodified filler incorporated composites, the scorch time gradually decreases after passing through the maximum values while treated composites remains its scorch time almost unchanged. Incorporation of filler may retard the formation of activator-accelerator pre-cursors due to the adsorption of them by the filler agglomerates. The composition analysis of the sludge confirmed that it mainly consist of magnesium ammonium phosphate hexahydrate. Ammonium salt which could increase the basic nature of the rubber compounds and hence supports the curing reactions. Therefore, increase in ammonium salt content with increasing filler loading speeds up the formation of the activator-accelerator complexes loading at higher filler loading as the surface area of filler agglomerates dose not increase proportionally to its volume. Therefore, decrease in scorch time of un-coated sludge rich compounds could be elucidated. It has been reported in literature that addition of various types of fatty acids at high concentrations could retard the curing reactions due to the various complex reactions associated 
with the soluble $\mathrm{Zn}$ ions formed in the compound (Coran, 1965, Poh \& Tang 1995, Hanafi Ismail \& Tajur Arus Ruhaizat,1997). In surface treated sludge, it has two major chemical substances namely Magnesium ammonium phosphates and stearic acid, both influence the curing reactions in two opposite directions. This may results in the almost unchanged higher scorch time of treated sludge incorporated compounds due to the compensation of opposite effects of each other. Therefore, it could be seen in Figure 4, that stearic acid coating has diminished the effect of filler loading on the scorch time of the treated sludge filled composites after a certain filler loading (20 phr).

In contrary to the effect on scorch time of the composites, there is a reduction in

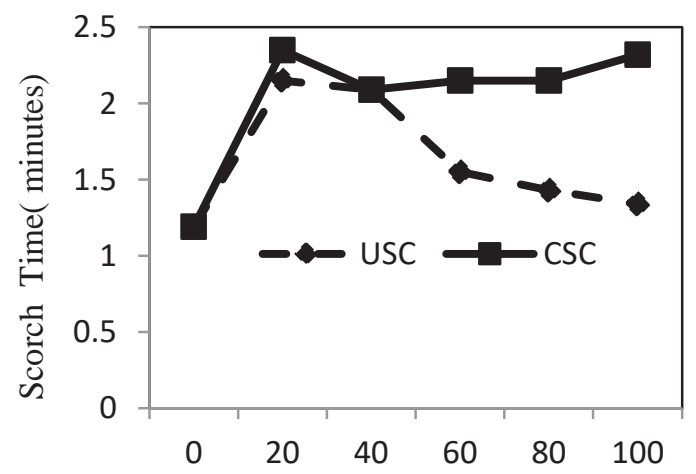

Sludge loading level (Phr)

Fig. 4. Scorch time vs sludge loading
$\mathrm{T}_{90}$ of the both types of filled compounds even at 20 phr sludge loading (Fig. 5). $\mathrm{T}_{90}$ of Uncoated Sludge Compounds (USC) exhibited a gradual reduction may be probably due to the presence of ammonium slats in the sludge. CSCs show an almost unaffected $\mathrm{T}_{90}$ values with sludge loading. The acceleration effect of ammonium salts and retardation effect of excessive fatty acid concentration in curing reactions of NR compounds incorporated with treated sludge explain this trend. Higher scorch time and lower $\mathrm{T}_{90}$ values of $20 \mathrm{phr}$ sludge filled compounds than that of NR gum compounds suggests that adsorption of curing ingredients by filler particles has become significant only at the low loading levels.

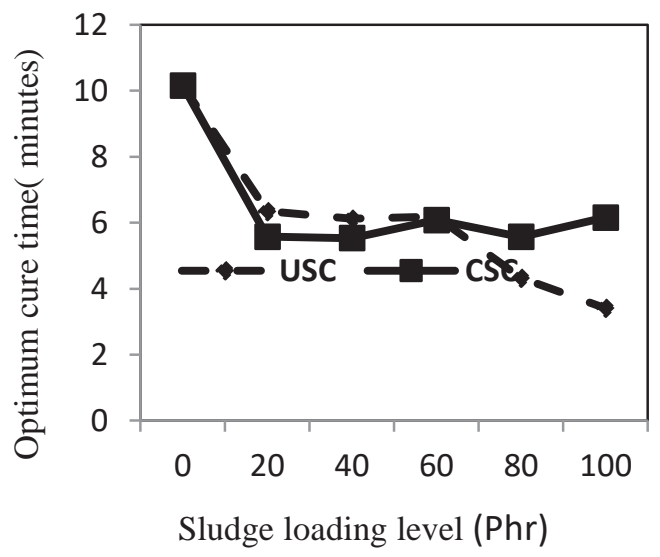

Fig. 5. Curve time vs sludge loading 
U M S Priyanka et al.

As it could be seen in Figure 6, for uncoated sludge filled composites, cure rate index gradually increases with the sludge loading. In other words, a faster cure rate is obtained for the composites with increasing sludge loading. This may be due to the ammonia complexes formed between ammonia and compounding ingredients yielding new substances which accelerate the curing process. Coating of sludge may delay the curing reactions as it could be acted as a barrier in emitting moisture and ammonia which cause to increase the cure rate (Egwaikhide et al., 2013) which is in par with the earlier observations made by other researchers (Poh \& Tang 1995, Hanafi Ismail \& TajurArus Ruhaizat 1997). From the results, it is evidenced that coating diminishes the effect of sludge loading on the cure rate of coated sludge filled NR compounds. Modification of sludge surface with stearic acid seems to allow incorporation of higher sludge loading without much adverse effect on the total cure time and processing safety.

As expected, incorporation of sludge has increased the minimum torque which indicates the processability of the rubber compound (Fig. 7). Higher the minimum torque, lower the material's processability. This is because of the restriction exerted by the filler particles against the mobility of rubber macromolecules. Maximum torque also increases for both types of composites, until it reached certain loading, beyond which maximum torque has again decreased with the sludge loading. When the composites are vulcanized, rubber molecules are cross linked and restrict their mobility in addition to the restriction applied by filler agglomerates. As the filler loading increases, larger agglomerates are formed in cross-linked rubber matrix and it may become unstable due to formation of larger agglomerates under experienced strain yielding lower torque values. It could be further seen in Figure 8 that the maximum torque of rubber compounds modified with stearic acid is lower than the corresponding uncoated sludge containing compounds. This may be due to the plasticizing effect of excess stearic acid in the modified sludge. 


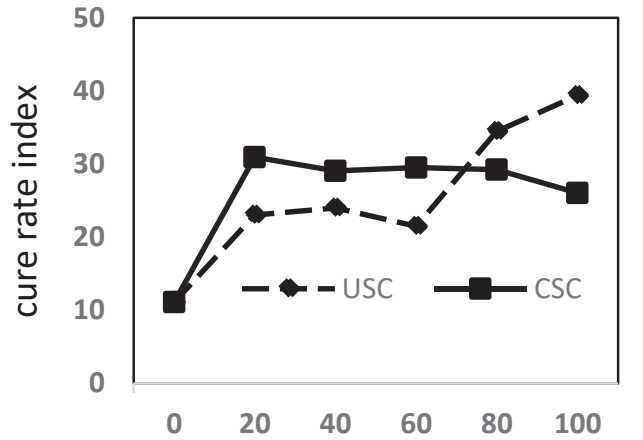

Sludge loading level (Phr)

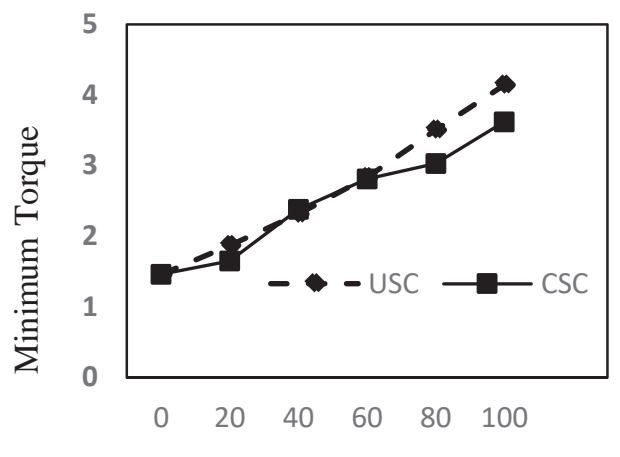

Sludge loading level (Phr)

Fig. 6. Cure rate index vs sludge loading

Fig. 7. Minimum torque vs sludge loading

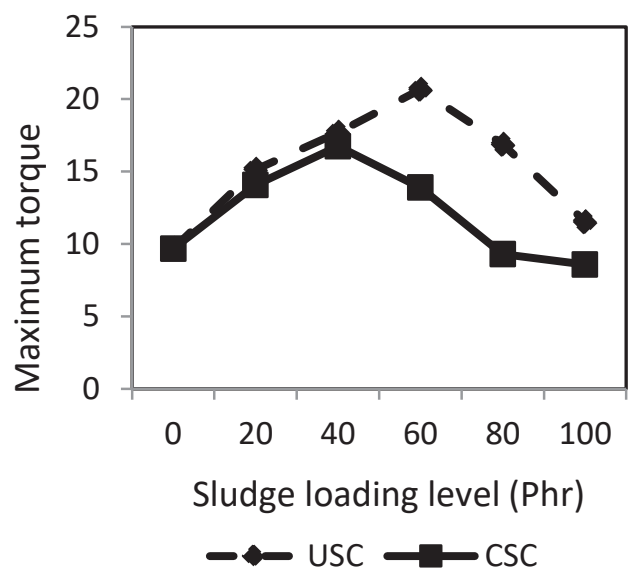

Fig. 8. Maximum torque vs. sludge loading

\section{Mechanical properties}

Figure 9 and 10 show the stress-strain responses of both unmodified (uncoated) and surface modified (stearic acid coated) latex sludge filled NR vulcanisates as a function of filler loading.

As expected, tensile strength (Fig. 9) of both uncoated and coated latex sludge filled vulcanisates was shown a reduction with the increase of sludge loading. In general, natural rubber gum compounds have shown strain-induced crystallization and the material crystallizes under increasing stress (Ismail et al. 2010). However, incorporation of sludge (i.e. both modified and unmodified latex sludge) may disrupt the strain-induced crystallization process of NR. In addition, as the filler loading increases, there is a trend to form larger sludge agglomerates resulting in inhomogeneous distribution of sludge 
U M S Priyanka et al.

agglomerates and poor interactions between sludge particles and rubber matrix and as a result of incompatibility of the filler and rubber. These agglomerates could serve as stress concentration points and flaws yielding poor tensile properties. Similar observations have been reported in literature for NR composites filled with other incompatible filler/natural rubber compounds (ShuhairiahDaud et al., 2016). However, it could also be inferred from the results that surface modification with stearic acid has improved the filler dispersion within the rubber matrix and hinder the sludge agglomeration to a certain extent as evidenced by the higher tensile strength values of coated sludge filled NR vulcanisates in comparison to that of uncoated sludge filled NR vulcanisates (Fig. 9), especially, at lower sludge loading up to 60 phr. Beyond 60 phr, coated and uncoated samples showed same values in tensile strength. This may be due to agglomeration of even coated latex sludge particulates at a higher loading.

According to Figure 10, \% elongation at break is gradually decreased with increase of uncoated latex sludge in the compounds while gradual increasing tendency is observed for the surface coated sludge filled compounds. This may be due to the availability of excess unreacted stearic acids that acted as a plasticizer in the NR compounds. Due to the lubricating effect created by unreacted stearic acid, sludge particles could slide over one another during stretching the matrix which resulted in an extra extension.

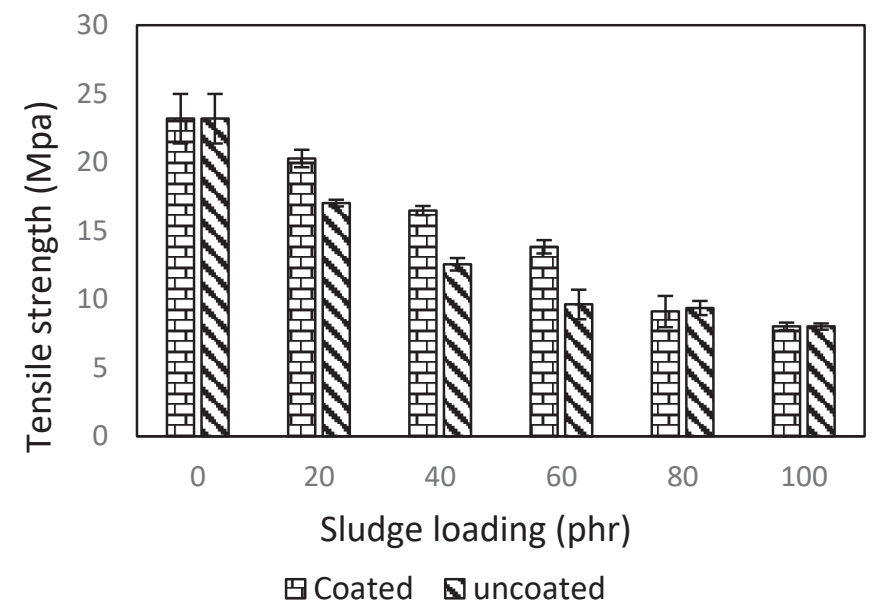

Fig. 9. Tensile strength of stearic acid coated and uncoated sludge containing vulcanizate 


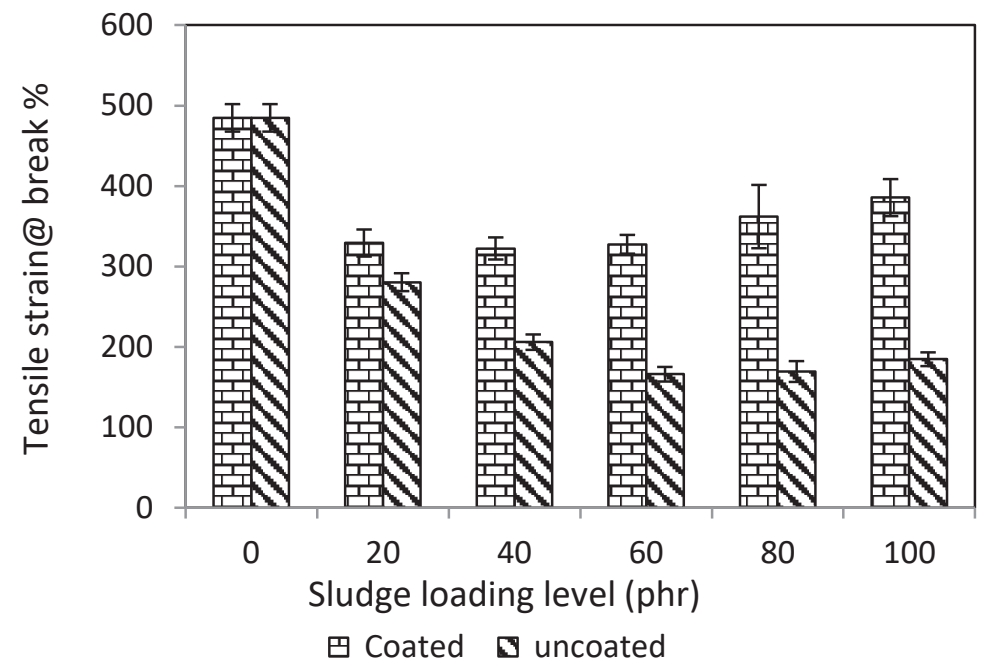

Fig. 10. The effect of filler loading on \% elongation at break of stearic acid coated and uncoated sludge containing compound

Stress at $100 \%$ elongation related to degree of filler to rubber interaction and the dispersion of the filler in elastomer matrix. Table 3 shows the effect of filler loading on modulus at $100 \%$ elongation. Modulus of the filled compound increased with an increase of filler loading. When further increase of latex sludge loading, the rubber content decreases resulting in increase in the stiffness of the composites. As there is no adequate rubber phase to wet the filler particles, the composite shows properties of a lightly bonded weak inorganic material yielding low modules values at higher filler loading. The lower modulus values registered for coated composites may be again due to the presence of free stearic acids in the composites. They also follow the same variation of modulus with the loading as uncoated composites.

Table 3. The effect of filler loading on $100 \%$ moduless of stearic acid coated and uncoated sludge containing compound

\begin{tabular}{lcc}
\hline $\begin{array}{l}\text { Filler loading } \\
\text { (sludge) (\%) }\end{array}$ & \multicolumn{2}{c}{ Moduless @ 100\% (Mpa) } \\
\hline 0 (unfilled) & Un-coated & Coated \\
20 & 4.003 & 1.707 \\
40 & 4.924 & 3.418 \\
60 & 5.399 & 3.886 \\
80 & 5.109 & 3.34 \\
100 & 4.036 & 2.314 \\
& & 1.736 \\
\hline
\end{tabular}

40 
U M S Priyanka et al.

Table 4. Mechanical properties of un-coated and coated sludge containing composites

\begin{tabular}{|c|c|c|c|c|c|c|c|c|}
\hline \multirow{2}{*}{$\begin{array}{l}\text { Filler } \\
\text { loading } \\
\text { (sludge) } \\
(\%)\end{array}$} & \multicolumn{2}{|c|}{$\begin{array}{l}\text { Hardness } \\
\text { (IRHD) }\end{array}$} & \multicolumn{2}{|c|}{$\begin{array}{l}\text { Resilience } \\
\text { (\%) }\end{array}$} & \multicolumn{2}{|c|}{$\begin{array}{l}\text { Compression } \\
\text { Set ( \%) }\end{array}$} & \multicolumn{2}{|c|}{$\begin{array}{c}\text { Abrasion as } \\
\text { volume loss } \\
\left(\mathrm{mm}^{3}\right)\end{array}$} \\
\hline & $\begin{array}{l}\text { Un- } \\
\text { coated }\end{array}$ & Coated & $\begin{array}{l}\text { Un- } \\
\text { coatec }\end{array}$ & Coated & $\begin{array}{l}\text { Un- } \\
\text { coated }\end{array}$ & Coated & $\begin{array}{c}\text { Un- } \\
\text { coated }\end{array}$ & Coated \\
\hline 0(unfilled) & \multicolumn{2}{|c|}{53.4} & \multicolumn{2}{|c|}{77.0} & \multicolumn{2}{|c|}{8.29} & \multicolumn{2}{|c|}{57.0} \\
\hline 20 & 64.1 & 60.5 & 71.5 & 72 & 10.93 & 8.57 & 77.85 & 197 \\
\hline 40 & 67.75 & 66.6 & 70.5 & 70 & 11.26 & 11.17 & 216.6 & 234 \\
\hline 60 & 72.58 & 63.9 & 69 & 62 & 13.96 & 11.56 & 258.8 & 300 \\
\hline 80 & 70.35 & 56.8 & 63 & 51 & 13.4 & 27.8 & 275.2 & 367 \\
\hline 100 & 65.39 & 55.1 & 54 & 49 & 26.6 & 32.5 & 313.4 & 360 \\
\hline
\end{tabular}

Both vulcanisates, it has shown that hardness (IRHD) is increased at lower loading levels of latex sludge while it decreases gradually when the loading level is high. However, at any given sludge loading level, coated sludge filled vulcanisate shows a lower value than that of uncoated sludge filled vulcanisate. This is attributed to the fact that unreacted stearic acid present in the rubber matrix acts as a plasticizer, resulting in reduced hardness.

There is no considerable reduction of resilience up to $60 \mathrm{phr}$ level indicating persistence of bouncing effect. It is evident from the results that there is no significant difference in compression set percentage in both coated and uncoated sludge incorporated compounds up to 60 phr level. Above $60 \mathrm{phr}$, there is a huge increment in percentage of compression set in both USC and CSC compounds. It could also be noted that at higher filler loading, percentage of compression has become higher in stearic acid coated sludge containing compounds when compared with uncoated sludge containing compounds.
In high filler loading levels such as 80 and $100 \mathrm{phr}$, agglomeration of filler is higher owing to poor filler dispersibility as well as the percentage of non vulcanisable materials in the composites. Consequently, lower cross linking density in the composites. It creates low strain recovery when the compression load relived resulting in high percentage of compression set. Higher compression set is exhibited in stearic acid coated sludge containing higher filler loading due to presence of higher quantity of free fatty acids which increase lubricating effect. Fillers could slide over one another when compressed resulting low recovery on relieve due to stearic hindrance of stearic acid. (Nik Nur Azza NikAdik et al., 2016). This may also lead to increase of percentages of compression set get higher at high loading levels.

Abrasion loss has significantly increased with incorporation of the sludge for both uncoated and coated composites. It has gradually increased with increasing sludge loading. Modified sludge containing compounds however, shows 
relatively lower abrasion resistance over the uncoated counterpart. Lubricating effect of the stearic acid discussed earlier may be responsible for this observation too.

\section{Conclusions}

Studies on chemical composition and structural characterization revealed that processed latex sludge has a structure resembling the crystalline material known as struvite. In addition to magnesium salts and phosphates, it contains rubber and other inorganic materials trapped within the latex sludge. Inorganic latex sludge is successfully converted into organo-philic by surface modification with stearic acid treatment. Unmodified latex sludge accelerates the vulcanization reaction of NR compounds as shown by cure rate index data. However, surface modification of latex sludge with stearic acid neutralizes the curing acceleration created by latex sludge and consequently curing characteristics of NR compounds are not affected by surface modified latex sludge.

Surface modification of latex sludge with stearic acid improves the uniform dispersion of sludge within the rubber composite and, moreover, enhances the compatibility between the two components. As a result, failure strength characteristics under tensile deformation of coated sludge filled composites (CSC) is improved compared to that of uncoated sludge filled composites (USC). Although surface treatment of sludge has a significant impact to prevent latex sludge agglomeration and enhances in sludge dispersion within the NR composite material, at higher loading levels of coated sludge, negatively affected on mechanical properties of composite due to higher amount of remaining free stearic acid in coating process. Therefore, this surface modified latex sludge material could be used in NR compounds as a semi reinforcing filler for different applications depending on the required vulcanizate properties.

\section{References}

Blow, C M (1971). Rubber Technology and Manufacture. $3^{\text {rd }}$ Edition, Butler Worth Publishing. 188pp.

Coran, A Y (1965). Vulcanization part VII. Kinetics of sulfer vulcanization of natural rubber in presence of delayed- action accelerators. Rubber Chemistry and Technology 38 (11), 1-14.

Mridul, D, Saptarshi, K, Saikat Das, G, Rabindra, M, Abhijit, B and Hari Shankar, S (2013). Effect to fly ash as filler in rubber: a comprehensive study of the vulcanisate properties of styrene butadiene rubber compounds". Elastomer and Tyre Research Institute (HASETRI) Progress. Rubber, Plastics and Recycling Technology 29 (3), 151-167.

Egwaikhide, A P, Okieimen, F E, Lawal, U (2013). Rheological and Mechanical properties of natural rubber compounds filled with Carbonized palm kernel husk and carbon black (N 330). Science Journal of Chemistry 1(5), 50-55.

Hanafi, I and Tajur, A R (1997). Effect of palm oil fatty acid on curing characteristics and mechanical properties of $\mathrm{CaCO}_{3}$ filled natural rubber compounds. Iranian Polymer Journal 6 (2) 97-104. 
U M S Priyanka et al.

Hepbium, C (1984). Filler Reinforcement of rubber. Plastic and Rubber International 9, 11-15.

Intiya, W, Thepsuwan, U, Sirisinha, C and Sae-Oui (2016). Possible use of sludge ash as filler in natural rubber. Journal of Material Cycles and Waste Management. 1-8.

Ismail, $\mathrm{H}$, Mahir, N A and Ahamad, Z (2010). Curing characteristics, Mechanical and morphological properties of kenaffibre/halloysite nanotubes hybrid-filled natural rubber compounds. Polymer - Plastics Technology and Engineering 49 (9), 938-943.

Maren, N, Marianeila, H Carmen, A and Curing G. (2006). Curing and Physical properties of natural rubber wood flour composite. Macromolecular Symposia 239(1), 192-200.

Mihajlovic, S, Sekulic, Z, Dakovic, A, Vucinic, D, Jovanovic, V and Stojanovic, J (2009). Surface properties of natural calcite filler, treated with stearic acid technology audit and production reserves. Ceramics 53 (4), 269.

Muniandy, K, Ismail and Othman, N (2012). Effect of partial replacement of rattan powder by commercial fillers on the properties of natural rubber composites. Bio Resources 7(4), 4640-4657.

NikNurAzzaNikAdik, Ong Hui Lin, HazizanMd Akil, Andrei VictDu Al Ray Vilagracia, Gil Nonato Santos (2016). Effect of stearic acid on tensile, morphological and thermal analysis of polypropylene (PP)/Dolamite (Dol) composites. Material Plastic 61-64.

Okiemen, E F, Akiniabi, A K, Aigbodion, A I, Bakare, I O, Oladogja, N A and Nig, J (2003). Polymer Science Technology 3, 233.

Okieimen, F E and Imanah, J E (2003). The characterization of agricultural waste products as fillers in NR formulation.
Polymer Science Technology 3(1), 210 216.

Okiemen, C O and Okiemen F E (2002). Effect of natural rubber processing sludge on the degradation of crude oil hydrocarbons in soil. Bio Resource Technology 82(1), 95-97.

Parkinson (1957). Reinforcement of Rubber. Lakemen and Co. London, 127.

Pangamol, P, Malee, W, Yujaroen, R, SaeOui, P and Siriwong, C (2018). Utilization of Bagasse Ash as a filler in natural rubber and Styrene Butadiene Rubber Composites. Arabian Journal of Science and Engineering. 43, 221-227.

Pongdhorn, S, Rakdee, C and Thanmthorn, P (2002). Use of rice husk ash as Filler in natural rubber vulcanizates, In comparison with other commercial fillers. Journal of Applied Polymer Science 83 (11), 2485-2493.

Priyanka, U M S and Rathnayake, U N (2011). NR latex sludge composition and Its activity as an inorganic filler for natural rubber compounds. Proceedings of the Fourth Symposium on Plantation Crop Research 335-342.

Poh, B T and Tang, W L (1995). Concentration effect of stearic acid on scorch behavior of epoxidized natural rubber. Applied Polymer Science 55 (3), 537-542.

Sae-Oui, P, Rakdee, C and Thanmathon, P (2002). Use of rice husk ash as filler in natural rubber vulcanizates, in comparison with other commercial fillers. Applied Polymer Science 83 (2), 2485-2493.

Shuhairiah, D, Hanafi, I and Azhar, A B (2016). Soil burial study of palm kernel shell-filled natural rubber composites: The effect of filler loading and presence of silence coupling agent. BioResources 11 (4), 8686-8702. 
Sludge from NR latex as a filler in rubber compounds

Ski, K B (1970). Engineering Material, properties and selection. Reston Publishing Company 426.

Stefov, V, Soptrajanov, B, Kumanovski, L, Lutz, H D and Engelen, B (2005). Infrared and raman spectra of magnesium ammonium phosphate Hexahydrate, (struvite) and its isomorphs analogues 111. Spectra of protiated and partially deuterated magnesium ammonium phosphate

hexahydrate. Journal of Molecular Structure 752, 60-67.
Weenusarin, I, Uthai, S, Chakrit and Pongdhorn S (2016). Possible use of sludge as filler in natural rubber. Journal Mater Cycles Waste management 4, 268.

Address for correspondence: Dr S Siriwardene, Deputy Director Research (Technology), Rubber Research Institute of Sri Lanka, Telewela Road, Ratmalana, Sri Lanka.

e-mail: susanthasiriwardena@yahoo.com 